\section{SINAIS DE FUMAÇA NA CIDADE: UMA SOCIOLOGIA DA CLANDESTINIDADE NA LUTA CONTRA A DITADURA NO BRASIL}

Henri Acselrad

Rio de Janeiro: Lamparina, FAPERJ, 2015.

Beatriz Silveira Castro Filgueiras

Universidade do Estado do Rio de Janeiro, Instituto de Estudos Sociais e Políticos, Rio de Janeiro, Rio de Janeiro, Brasil

Somando-se aos esforços recentes de produção de uma memória acerca da ditadura militar brasileira (1964-1985) em suas múltiplas dimensões, é muito bem-vinda a publicação de Sinais de fumaça na cidade: uma sociologia da clandestinidade na luta contra a ditadura no Brasil, pela editora Lamparina, com apoio da Fundação de Amparo à Pesquisa do Estado do Rio de Janeiro (FAPERJ). Nesse livro, Henri Acselrad - professor titular do Instituto de Pesquisa e Planejamento Urbano e Regional da Universidade Federal do Rio de Janeiro (IPPUR/UFRJ) - oferece uma aguçada e sensível análise da experiência da militância clandestina, da sua inserção no contexto, no espaço e no cotidiano urbanos. Baseado em uma pesquisa que resultou também em um artigo premiado $^{1}$, o livro apresenta uma abordagem inédita e inovadora, iluminando questóes ainda pouco trabalhadas sobre a experiência de luta contra a ditadura. De modo especial, o livro traz indagações sobre as próprias condições de possibilidade da política ou, nas palavras do autor, "sobre o lugar onde a política teria se refugiado quando esta fora, pelo regime de exceção, inviabilizada; [...] em que interstícios, em que frestas da vida social, a política se fazia então possível e sob que formas?" (p. 19).

Apoiando-se em um amplo conjunto de narrativas - entrevistas semiabertas a 50 ex-militantes clandestinos entre 1969 e 1973 na cidade do Rio

1 Entre a lua e a rua: uma topologia social da clandestinidade política na cidade do Rio de Janeiro, que deu origem a este livro, foi eleito o melhor artigo no Prêmio Milton Santos concedido pela Associação Nacional de Pós-graduação e Pesquisa em Planejamento Urbano e Regional (ANPUR), em 2013. de Janeiro, dados de literatura testemunhal, levantamento em jornais diários da época -, Acselrad analisa os movimentos de ruptura e de adaptação situacional e social e as condiçóes da ação política que marcaram a experiência da clandestinidade, isto é, os "processos através dos quais os militantes foram conduzidos a estabelecer, nos espaços sociais em que buscaram se inserir, laços de outra ordem, sob novas condiçôes e pretextos" (p. 15). Por meio da busca de elementos comuns na reconstrução das lembranças e experiências individuais, o autor procura destacar "o processo coletivo que reuniu estes indivíduos em um movimento comum de entrada, com novos personagens, numa cena urbana preexistente; o deslocamento socioespacial em direção ao cenário físico social concreto das áreas suburbanas, para onde a luta contra a ditadura nas cidades, em grande parte, os conduzira" (p. 21).

Além disso, de modo indireto, Acselrad tenta iluminar os "impactos” da militância clandestina no cotidiano da cidade, em particular nos subúrbios, nos bairros populares e nas fábricas onde ela se refugiou, tangenciando a percepçáo e o estranhamento dos moradores sobre sua presença e comportamento. A tensão e a vigilância permanentes marcam os contextos de interação entre a militância e aqueles com os quais esta conviveu, assim como as condiçóes de possibilidade de abertura e construção de algum campo de significados compartilhado, no sentido de "desnaturalizar" a ditadura junto aos populares.

No desenvolvimento de sua análise, Acselrad mobiliza, de modo simultâneo e complementar, dois procedimentos analíticos. Por um lado, põe em ação uma "sociologia histórica das circunstâncias" que dialoga com o contexto social e político do regime de exceção a partir do fechamento autoritário da esfera e do espaço públicos. Ele retira daí a figura do "militante clandestino" como personagem coletivo e histórico, explorando a dimensão organizada das experiências, dos discursos, dos imaginários e representaçóes sobre a clandestinidade política. Por outro lado, o autor faz uso da interpretação microssociológica do cotidiano e da valorização da experiência social da clandestinidade, iluminando, assim, a vivência do que poderia parecer um "autoexílio" e a

DOI: http://dx.doi.org/10.22296/2317-1529.2016v18n1p167 
questão identitária, a inserção da clandestinidade no contexto e no espaço urbanos, o convívio e as relaçôes entre militantes, vizinhos e pessoas próximas, as açôes situadas e seus espaços localizados de significação, a fim de encontrar os vestígios que permitiriam reconstituir, ainda que tangencialmente, essas "peculiares situações de interação” (p. 34).

Ao longo das seçôes/capítulos em que se organiza o livro, Acselrad explora, tateando os chamados "sinais de fumaça", diferentes dimensóes da experiência da luta política clandestina, em particular os modos como a militância integrou o cotidiano das cidades e buscou se inserir nos espaços onde se refugiou para melhor se diluir no seio da população.

De início, são postas em destaque a "topologia social da clandestinidade política" na cidade do Rio de Janeiro e sua espacialidade própria e a topografia simbólica que situou a militância clandestina em um espaço de posiçóes relativas em que "ganha[ra]m destaque, no universo simbólico de seus protagonistas e analistas, antes de tudo, distâncias e altitudes" (p. 32). Por um lado, na perspectiva dos militantes, observa-se a vivência de um paradoxo entre a percepção do isolamento - da restriçáo e do "confinamento" às margens de uma cidade convertida em mecanismo de vigilância - e, ao mesmo tempo, a sensação de alargamento físico e simbólico da urbe, advinda da experiência de errância e mobilidade, da mudança de localização, de lugares e trajetos, do acesso e do encontro com universos e cenários sociológicos distintos. Por outro lado, nota-se também que os militantes sentiam as distâncias entre as pretensôes revolucionárias e as condições concretas de sua realização.

Acselrad afirma que a sociologia da clandestinidade política se caracteriza pelas "distâncias próprias a uma comunicação problemática entre a cidade vivida e o espaço público", posto que "o padrão de interação estabelecido entre os clandestinos e os citadinos configurava traços de proximidade e distância similares aos da figura do estrangeiro, do viajante ou do estranho, marcados pela mobilidade" (p. 48-49, grifos do original). Distâncias e altitudes que apontavam, enfim, para a imaginaçáo - compartilhada, a seu modo, por militantes e sociedade - do "descolamento" dos clandestinos da "realidade", como se eles resistissem num plano "aéreo" e, de maneira pontual, irrompessem violentamente no chão das cidades, de modo dramático, como no caso das açóes armadas.

Tal senso comum sobre a distância e o descolamento da militância clandestina e sobre a resistência contra o regime militar também se refletia ou se reforçava, de um modo geral, nas narrativas da imprensa e nos relatos acerca das açóes, dos militantes e do próprio exercício da crítica política. A grande imprensa - atravessada pela censura e/ou pelo apoio explícito ao regime - operava como recurso específico de persuasão, já que era "frequentemente acionada pelas forças de exceção na expectativa de fazer pender as subjetividades coletivas em favor da ação repressiva" (p. 75). Tendo isso em vista, a análise dirige-se à forma como foi construído o protesto armado como objeto jornalístico e sua influência nos modos como os moradores das cidades perceberam a militância clandestina e suas açóes.

Seguindo um roteiro relativamente rígido, as narrativas da imprensa apoiavam-se na construção de uma oposição entre o personagem do "terrorista" e o "membro ordeiro da cidade" - seja o "transeunte", no exercício de sua mobilidade, seja o "morador"/“vizinho", membro enraizado da comunidade, retratados, "via de regra, como aqueles que tinham o curso de seu cotidiano, ordeiro e relativamente regular, perturbado pela ação clandestina" (p. 92). No caso específico das açóes armadas, os enquadramentos dramáticos oscilavam entre metáforas de guerra, da luta do bem contra o mal, e/ou metáforas de quebra-cabeças, de uma "trama confusa e inexplicável” (p. 113), atravessadas pela figura polimorfa do "subversivo", pela incriminação de certos comportamentos urbanos e pela criminalização da ação política em si, náo apenas dos seus métodos, mas também de sua substância.

Com as áreas centrais da cidade sendo objeto de uma vigilância cada vez mais estrita, foram nas áreas periféricas, nos subúrbios e bairros populares que os militantes procuraram clandestinamente refugiar-se. $\mathrm{O}$ abandono de seus lugares de origem expressava, entâo, a busca por brechas para a resistência política, descortinando, para os militantes, "uma outra cidade e uma outra relação com ela" (p. 125). Mais jovens e mais escolarizados que a média da população residente nessas áreas, a presen- 
ça deles - "fora de lugar" - causava estranhamento entre os moradores e exigia dos militantes atenção, negociação e ajustes permanentes na adaptação e interação com a vizinhança, no intuito de manter algum controle sobre a impressão que causavam e os sinais que emitiam. Tal cenário expóe não apenas a teatralidade do cotidiano e, em particular, da cena urbana - isto é, a diversidade de públicos e máscaras presentes na cidade -, mas também o próprio caráter "dramático" da experiência da clandestinidade, na qual encenaçáo e autenticidade - da identidade e dos papéis desempenhados pelos militantes em copresença e interação - encontravam-se profundamente entrelaçadas no cruzamento entre elementos da identidade original e da identidade assumida pelos militantes. "A militância clandestina, com seus múltiplos personagens, atravessou as cidades como em uma cena teatral” (p. 165). A ficção, no entanto, não era experimentada somente pelos militantes, cuja dramatização planejada e controlada constituiria uma "fiç̧âo de primeiro grau" (p. 171, grifo do original), mas também envolvia aqueles com quem interagiam e que, igualmente, buscavam adaptar-se àquelas presenças incomuns.

Em todo caso, apesar do fechamento da esfera pública, da percepção de apatia e mesmo a eventual complacência dos populares com o regime militar, da tensão e vigilância permanentes e da estranheza que a presença deles nos subúrbios e bairros populares causava, os militantes, com seus novos personagens, teciam laços e estabeleciam relaçóes com os moradores da cidade, com quem compartilhavam a moradia, o trabalho e o cotidiano. Eram também esses laços e situaçóes de interação que continham em si a possibilidade de ampliação da crítica e da resistência ao regime de exceção. No entanto, o peso das estruturas de vigilância e repressão e os estreitos limites da ação política naquele contexto constituíram graves obstáculos, o que fez com que tais relaçóes permanecessem efêmeras, os consensos de interação, precários, os espaços e situações de publicização da crítica, sempre tensos e abortados, e que o seu tempo fosse fugaz, nunca suficiente para dotá-las plenamente de sentido. "O encontro entre intelectuais e trabalhadores ou moradores de subúrbios, nas condições da clandestinidade, teve caráter pontual e fragmentário, não tendo podido alcançar densidade suficiente para dar lugar a processos coletivos" (p. 198).

Dessa forma, o que Acselrad chama de "zona cinzenta urbana” - isto é, os lugares e/ou situaçóes de interação e convivência dos militantes com a sociedade em geral, em particular com as classes populares -, embora contivesse a possibilidade de abertura e constituição de "microespaços" ou "microarenas" públicas, viu-se permanentemente frustrada pelo peso da vigilância e da estrutura repressiva, bloqueando os processos de expansão e publicização da ação e da crítica políticas. Contudo, se as imagens do desencontro, do distanciamento e do descolamento da militância clandestina são recorrentes quando se assinala apenas certa "perda de sentido de realidade por grande parte dos militantes", no contexto do regime de exceção, tal situação afetava, em verdade, o conjunto da sociedade. "Ou seja, todos eram, de algum modo, então obrigados a conviver com 'substitutos do real'. [...] Pois não é fato que o fechamento autoritário da esfera pública havia tido por fim lançar a todos num voo relativamente cego?” (p. 190).

Ao investigar a experiência urbana da militância clandestina durante a ditadura militar brasileira, Acselrad nos convida a refletir acerca do lugar e das possibilidades do exercício da política em contextos de fechamento da esfera pública e de silenciamento da crítica; exercício que, longe de encerrar-se no entendimento daquele período histórico, abre horizontes de reflexão para o contexto contemporâneo, de modo a "problematizar o passado para pensar a singularidade do presente" (p. 18). Assim, o autor encerra o livro jogando luz sobre o contexto pósditadura, refletindo sobre as heranças do regime militar e sobre as vicissitudes da sua superação nas últimas décadas. Ele destaca a violência de Estado, a militarização das polícias, a impunidade de torturadores e a degradação da política, sustentadas pelo desenvolvimento do que designa como "democracia imagética” (p. 202), cuja estabilidade, apenas aparente, se ancora em consensos simbólicos, ou mesmo fictícios, e cujos sintomas de ruptura tornam-se crescentemente visíveis.

Se, no contexto da eclosão dos movimentos de 2013, tal ruptura se expressava ainda de manei- 
ra positiva, sinalizando o fortalecimento da mobilização social e a ocupação da esfera pública, o debate sobre a politização dos conflitos existentes na sociedade, dos seus objetos e dos valores que os constituem, tal conclusão torna-se particularmente inquietante no momento que atravessamos em 2016, no qual assistimos à polarização e à radicalização políticas, agravadas pela crescente tensão social. Momento que revela também, de modo bastante sensível, a fragilidade dos valores democráticos, dos avanços consagrados na Constituição de 1988 e da própria memória acerca do regime militar, sobre a qual claramente não existe consenso. A evocaçáo perigosa - e criminosa, inclusive - da pertinência da volta do autoritarismo, assim como a apologia da tortura, da perseguiçáo moral de opositores e da consagração pública de notórios torturadores evidenciam a necessidade e a urgência de disputarmos a memória histórica da ditadura militar brasileira, reivindicando e reafirmando o compromisso com a sua superação.

Nesse sentido, Sinais de fumaça na cidade, além de ser uma valiosa contribuiçáo para o registro e compreensão daquele período histórico - e da experiência urbana da clandestinidade política, especificamente -, constitui uma poderosa ferramenta de questionamento do presente e do que, caso não haja um tratamento cuidadoso da história, pode ainda estar por vir.

Beatriz Silveira Castro Filgueiras é bacharel em Ciências Sociais pela Universidade Federal de Minas Gerais (UFMG); mestre em Planejamento Urbano e Regional pela Universidade Federal do Rio de Janeiro (UFRJ); doutora em Sociologia pelo Instituto de Estudos Sociais e Políticos da Universidade do Estado do Rio de Janeiro (IESP/UERJ).

E-mail: beatrizfilg@yahoo.com.br. 